\title{
Sulfur as a binding agent of aggregates in explosive eruptions
}

\author{
Teresa Scolamacchia $\cdot$ Donald B. Dingwell
}

Received: 31 March 2014 / Accepted: 10 September 2014 / Published online: 24 September 2014

(C) Springer-Verlag Berlin Heidelberg 2014

\begin{abstract}
Understanding the mechanisms that govern ash aggregation is of critical importance in volcanology. Aggregation reduces the residence time of ash $(\leq 2 \mathrm{~mm})$ in the atmosphere strongly, by enhancing the sedimentation of finer-grained material generated during explosive eruptions. To date, experimental studies have focused on the expectation that water provides the strongest bonds between particles to form spherical to oblate aggregates (typically less than or equal to a few $\mathrm{mm}$, occasionally up to several $\mathrm{cm}$ ) preserved in pyroclastic deposits. Under water-rich conditions, individual accreted particles rarely exceed $1 \mathrm{~mm}$. In pyroclastic density current deposits produced during the 1982 eruption of El Chichón, Mexico (which emitted 7.5 Tg of $\mathrm{SO}_{2}$ in the atmosphere), aggregate particles one to several millimeters, strongly cemented by a S-rich film, are common. They exhibit similarities with aggregates found in sulfur cones at Poás volcano, Costa Rica. We propose that sulfur is the binder between the silicate grains. Such a binding capacity implies a relatively fluid behavior of sulfur such as might be expected in the low viscosity temperature regime just above its melting point. If so, then the explosive ejection of sulfur during eruptions, combined with its ability to act as a cement for particles $>2 \mathrm{~mm}$, would imply that size fractions of lapilli can be efficiently removed from eruptive clouds a few kilometers from the vent. Such an aggregation mechanism would have important implications for pyroclast dispersal models and hazard assessment.
\end{abstract}

Keywords Aggregation $\cdot$ Sulfur explosive eruptions $\cdot$ lapilli and ash

Editorial responsibility: C. Oppenheimer

T. Scolamacchia $(\bowtie) \cdot$ D. B. Dingwell

Ludwig Maximilian University, Theresienstr. 41, 80333 Munich,

Germany

e-mail: scolamacchia@min.uni-muenchen.de

\section{Introduction}

In explosive eruptions, ash $(\leq 2 \mathrm{~mm})$ typically represents a large fraction of the total erupted mass. It is dispersed in the atmosphere by vertical plumes and/or pyroclastic density currents (PDCs). Airborne measurements within relatively dilute outflow regions of eruptive clouds, where large particles have settled out, indicate that fine ash $(1 \mu \mathrm{m}$ to $1 \mathrm{~mm})$ could yield number concentrations of up to hundreds per cubic centimeter (Hobbs et al. 1982, 1991).

Aggregation reduces the transportability of ash and thereby the distances at which a given concentration may be expected in volcanic clouds. This aggregation-induced reduction in atmospheric residence time results from the enhanced settling velocity of aggregates compared with single particles (Sparks et al. 1997).

For this reason, research has been undertaken: to understand the causes responsible for the formation of different types of aggregates, to reproduce experimentally their internal structure, and to model their transport and depositional behavior (see below).

Among the aggregates described in pyroclastic deposits worldwide, two particular occurrences, i.e., those described in PDC deposits emplaced during the 1982 eruption of $\mathrm{El}$ Chichón (Mexico), and the 2005 eruption of Ilamatepec (El Salvador), despite their otherwise similar character (in dimensions, morphology, and internal structure) to aggregates described elsewhere, differ from the others in exhibiting an orange to red, micrometer-thick film, cementing individual particles (Scolamacchia et al. 2005, 2010). Semiquantitative EDS analyses, as transects across the film, and compositional mapping of the aggregates indicate that the binding film consists of an amorphous phase rich in $\mathrm{S}$ and $\mathrm{Fe}$ and minor $\mathrm{P}$, with variable amounts of $\mathrm{K}, \mathrm{Ca}, \mathrm{Na}$, and $\mathrm{Mg}$, depending on the particle to which they adhere. This particular compositional range has been attributed to the precipitation of an 
amorphous phase from acid solutions within the volcanic clouds derived from the contemporaneous ejection of magmatic and hydrothermal fluids and groundwater (Scolamacchia et al. 2005).

Here, we propose an alternative explanation for the formation of these aggregates and for the origin of the binding substance between individual grains, based on textural characteristics and further analyses.

\section{Background}

The presence of aggregates has, in the past, been inferred from the observation of a polymodal particle size distribution of fallout deposits and is the most viable mechanism to explain the occurrence of secondary thickness maxima in such deposits (i.e., Sarna-Wojcicki et al. 1981; Carey and Sigurdsson 1982; Brazier et al. 1982, 1983).

In this respect, Durant et al. (2009) have proposed that the secondary thickening in fallout deposits of the 1980 eruption of Mount St. Helens, observed at $325 \mathrm{~km}$ ENE from the vent (Ritzville maxima of Sarna-Wojcicki et al. 1981), was produced primarily by the aggregation of particles with modal diameters of $19 \pm 3 \mu \mathrm{m}$, transported into the upper troposphere, where they initiated ice nucleation. The increase in mass loading of the eruptive cloud, due to ice formation, would have caused its subsidence until reaching an altitude of $6.9 \mathrm{~km}$, where ice melting would have caused the fallout of the fine ash fraction within a few hours.

Spherical to oblate pellets $(100 \mu \mathrm{m}$ to several tens of $\mathrm{mm}$ in maximum diameter and, in some cases, few cm, Fig. 1), with or without an internal structure and/or a solid core, are commonly visible in fallout, and PDC deposits produced by a variety of eruption types (e.g. Reimer 1983; Sheridan and Wohletz 1983; Wilson 2001; Ritchie et al. 2002).

Observations during explosive eruptions have reported the fallout of 1 to $10-\mathrm{mm}$ diameter aggregates, from plumes that are a few to tens of kilometer high, indicating that fine-ash particles frequently fall as larger aggregates (e.g., Brazier et al. 1982; Tomita et al. 1985; Gilbert and Lane 1994; Bonadonna et al. 2002).

Analysis of high-speed video recordings of ash falling from volcanic clouds during the 2010 eruption of Eyjafjallajökull volcano (Iceland) has yielded the interpretation that aggregation caused a tenfold increase in mass sedimentation at distances of $7 \mathrm{~km}$ from the vent (Taddeucci et al. 2011). Aggregates dominated over single particles in size fractions between $500 \mu \mathrm{m}$ and $2 \mu \mathrm{mm}$, and $<250 \mu \mathrm{m}$, implying that without aggregation, only individual particles between $1.5 \mathrm{~mm}$ and $355 \mu \mathrm{m}$ in size would have been able to settle from the cloud.

Several studies have attempted to determine the optimal conditions necessary for the scavenging of particles into aggregates, by experiments (Gilbert and Lane 1994;

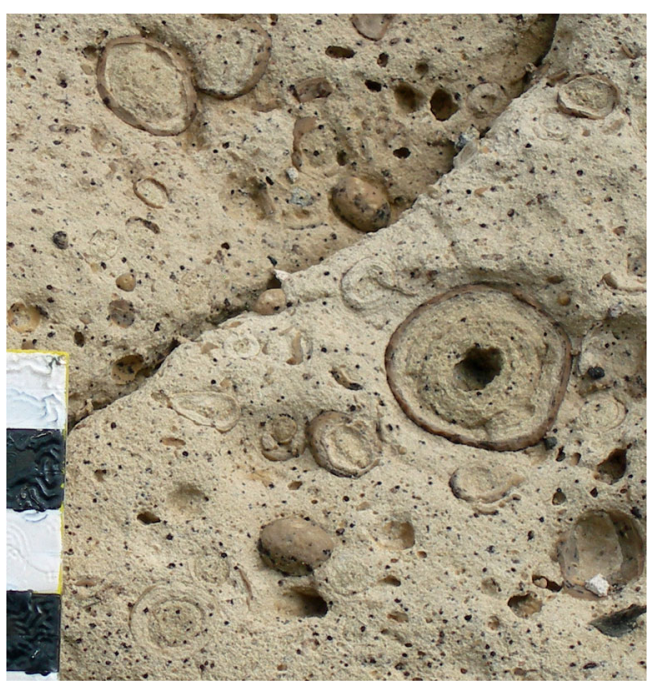

Fig. 1 View of pellets with a concentric lamination (accretionary lapilli) and fragments of them, embedded in the 273-ka Poris ignimbrite, Tenerife (flow unit 4) (courtesy of M. Branney). Scale in centimeter to the left of the photo

Schumacher and Schmincke 1995; James et al. 2002; Telling and Dufek 2012; Van Eaton et al. 2012a; Telling et al. 2013) and by numerical models (Veitch and Woods 2001; Textor et al. 2006a, b; Durant et al. 2009; Costa et al. 2010; Folch et al. 2010; Van Eaton et al. 2012b) in order to infer the areas in both volcanic plumes and pyroclastic density currents (PDCs), where aggregation could be favored.

\section{Binding forces}

Electrostatic forces between charged, recently fragmented, or colliding particles and capillary forces due to the action of liquid water have both been proposed to play a role in aggregation processes.

Lane et al. (1993) and Gilbert and Lane (1994) suggested that the growth of aggregates is controlled by collisions among liquid-coated particles, due to the ability of liquid bridges to dissipate the kinetic energy of particle collisions, promoting particle capture. Aggregation efficiency should thereby increase as particle diameter decreases, varying from nearly 100 to $5 \%$ for particles 1 to $100 \mu \mathrm{m}$ in size, respectively (Gilbert and Lane 1994). Liquid water could therefore explain the formation of sub-millimeter- to centimeter-sized aggregates found in the stratigraphic records (e.g., Schumacher and Schmincke 1991, 1995; Bonadonna et al. 2002; Brown et al. 2010, 2012), by providing stronger bonds between particles with respect to short-term, but long-range, electrostatic forces between charged, recently fragmented, ash, which by contrast would only form fragile, ephemeral, aggregates $<1 \mathrm{~mm}$ in maximum size (James et al. 2002).

More recently, experiments indicated that a critical residence time ( $>50 \mathrm{~min})$ in an atmosphere at relative humidity $>71 \%$ would allow the formation of a film of water around 
particles 90 to $150 \mu \mathrm{m}$ in size, determining an increase in the aggregation efficiency by more than $60 \%$ (Telling et al. 2013).

Various experiments agree that an optimum amount of liquid water, around $15 \mathrm{wt} \%$ (30 vol\%), is required to form well-developed spherical aggregates from a polymodal ash population (Schumacher and Schmincke 1995; Van Eaton et al. 2012a). At such contents, aggregates would already be strong enough to survive impacts with the ground falling $1 \mathrm{~m}$ (Van Eaton et al. 2012a), without the presence of secondary minerals (e.g., gypsum and sodium chloride) precipitated from acid solutions (Gilbert and Lane 1994). At $~ 15 \mathrm{wt} \%$ water, the particles scavenged into aggregates are mostly $<250 \mu \mathrm{m}$ in size. Even for liquid contents $>15 \mathrm{wt} \%$, particles $>200 \mu \mathrm{m}$ are rarely incorporated into aggregates, and below $20-25 \mathrm{wt} \%$, all particles $>125-250 \mu \mathrm{m}$ are also preferentially excluded (Van Eaton et al. 2012a). Aggregation would be even more strongly size-selective for water contents $<5 \mathrm{wt} \%$, at which only particles $<63 \mu \mathrm{m}$ are preferentially scavenged from the parent mixture (Van Eaton et al. 2012a). Such aggregates are fragile, and grain-dispersive forces can easily overcome the binding forces due to liquid water (Schumacher and Schmincke 1995).

Experimental results also indicate that particles $\geq 1 \mathrm{~mm}$ are preferentially excluded from aggregation, except for liquid water contents $>20-25 \mathrm{wt} \%$ ( $45-50 \mathrm{vol} \%)$. At such contents, particles up to $2 \mathrm{~mm}$ are scavenged by pockets of oversaturated ash (Schumacher and Schmincke 1995; Van Eaton et al. 2012a, b), which nevertheless rapidly lose their strength, merging into slurries (liquid pellets, or AP3, of Brown et al. 2012), which are unable to persist as stable aggregates (as observed in real eruptions, i.e., "mud rain" of Gilbert and Lane 1994).

When eruptive plumes rise in the atmosphere, water can undergo phase transformations. The formation of ice inside plumes can occur within the first $2-3 \mathrm{~km}$ of ascent, depending on the season and latitude (Sparks et al. 1997). Higher up, the formation of ice can be significant and dominate in comparison to liquid water, triggering aggregation processes (Textor et al. 2006b).

Heterogeneous ice nucleation triggered by volcanic ash occurs at lower supersaturation and higher temperatures, with respect to homogeneous ice nucleation in the presence of pure water $\left(-35\right.$ and $\left.-40{ }^{\circ} \mathrm{C}\right)$. According to Durant et al. (2008), particles $1 \mu \mathrm{m}$ to $1 \mathrm{~mm}$ in size are able to nucleate ice at temperatures between -10 and $-20^{\circ} \mathrm{C}$; differences in the bulk silica content (i.e. basaltic vs. rhyolitic compositions) have only a weak effect on the onset of freezing.

Nevertheless, experiments using hailstones (Van Eaton et al. 2012a) indicate that solid ice preferentially scavenges particles $<63 \mu \mathrm{m}$ (mostly $<34 \mu \mathrm{m}$ ), in the absence of a liquid phase. Particles are initially accreted by electrostatic forces generated by particle collisions; more permanent bonds develop only tens of seconds or minutes afterwards, due to ice sintering, at subfreezing temperatures. The timescale of ice sintering nevertheless limits the ice-binding ability because particle collisions, lasting only milliseconds in the absence of electrostatic or capillary forces, are insufficient to keep icecoated particles in contact long enough for sintering (Van Eaton et al. 2012a).

Aggregate formation should therefore depend on the fraction of water or ice available at the particle surfaces. Hygroscopic compounds could accelerate sintering process, promoting the development of thin liquid layers on ice surface, even at subfreezing temperatures (Van Eaton et al. 2012a). In fact, experiments by Textor et al. (2006a) indicated that acid solutions (i.e., mixtures of water and soluble gases like $\mathrm{SO}_{2}, \mathrm{H}_{2} \mathrm{~S}$, $\mathrm{HCl}$, and $\mathrm{HBr}$ ), or soluble salts, coating particles, are able to lower the freezing point of ice, increasing the mass of liquid water, accelerating aggregation processes, due to an increase in liquid water availability (Textor et al. 2006b). Nevertheless, according to Lathem et al. (2011), the uptake of liquid water on particles $<125 \mu \mathrm{m}$ due to hygroscopic compounds would be unlikely below $100 \%$ relative humidity $(\mathrm{RH})$ and would not increase the aggregation efficiency even above $80 \% \mathrm{RH}$.

\section{Numerical models and field observations}

The entrainment of ambient air, rich in water vapor, either at the fringes of eruptive plumes or during the horizontal movement of pyroclastic density currents (PDCs), can provide the amount of water necessary for aggregation, considering that the amount of water as exsolved volatiles during explosive volcanic eruptions is negligible in this process (Sparks et al. 1997).

Numerical models (Veitch and Woods 2001; Textor et al. 2006a, b; Durant et al. 2008; Folch et al. 2010; Costa et al. 2010) focused on moderate to large intensity explosive eruptions of $\left(\leq 10^{7}\right.$ and $10^{8} \mathrm{~kg} / \mathrm{s}$ M.E.R.), which generate tens of kilometer-high eruptive columns that reach the stratosphere. Aggregation would be related to the concentration of particles within eruptive clouds, the fraction of liquid water or ice inside them, and the intensity of eruptions, which determines the height at which the process can occur (Veitch and Woods 2001; Textor et al. 2006b; Costa et al. 2010).

Even considering the accretion capacity of ice inside eruptive clouds (e.g., Textor et al. 2006a, b; Durant et al. 2008; 2009; Costa et al. 2010), all numerical models agree that liquid water provides the stronger binding forces between particles since they are based on experimental results, which use water exclusively as a binding agent. Therefore, they concentrate on size fractions $\leq 250 \mu \mathrm{m}$ due to the higher probability of these particles' sizes to be incorporated as stable aggregates (e.g., Veitch and Woods 2001; Textor et al. 2006a, b; Durant et al. 2008; Costa et al. 2010; Folch et al. 2010). 
Based on the distribution of different types of aggregates within different layers of ignimbrite couplets in Tenerife, Brown et al. (2010) proposed that the internal structure of aggregates reflects the amount of condensing water with height inside thermally stratified PDCs. Structureless pellets (AP1 of Brown et al. 2012) made of particles with median grain sizes $<100 \mu \mathrm{m}$, abundant in capping, laterally continuous, and clast-supported fallout layers, form within the coignimbrite ash plumes. As they settle in the lower, more turbulent, and progressively hotter portions of the densitystratified pyroclastic current, they accrete layers of finergrained particles (10 to $15 \mu \mathrm{m}$ ), forming pellets with a concentric structure (accretionary lapilli, Brown et al. 2010; or AP2 of Brown et al. 2012). These concentric pellets are preserved in the lower, matrix-supported, ignimbrite layers, together with fragments of them, indicating that fragmentation occurred via collisions during horizontal transport (Fig. 1). The accretion of finer-grained rims, requiring only a minimum of condensation, would therefore attest the higher temperatures and lower water contents existing in the lower portions of the currents. Similar vertical variations in the distribution of aggregates have been described by Schumacher and Schmincke (1991), in pyroclastic flow deposits at Laacher See (Germany), by Branney and Brown (2011) in meteorite impact ejecta deposits (Stac Fada Member) from an unknown source in Scotland and by Van Eaton and Wilson (2013) in the eruptive units of the $25.4 \mathrm{ka}$ Oranui eruption of Taupo (New Zealand). Based on the distribution of different types of aggregates, it would be possible to discriminate deposits emplaced by different portions of a density current (pyroclastic or impactoclastic) (i.e., upper, current-derived buoyant plume or unsteady lower body of the current). Nevertheless, according to Schumacher and Schmincke (1991), such a distinction is difficult to make for PDC deposits produced by hydromagmatic activity (i.e., base surges), because "mixed populations" of aggregates occur in the same depositional layer. Beyond supporting the model proposed by Brown et al. (2010), Van Eaton and Wilson (2013) point out that although linked to the passage of PDCs, the growth of extremely fine-grained $(<10 \mu \mathrm{m})$ outer rims does not necessarily form within the laterally moving currents, being more likely dependent on the supply of fine particles rather than heat or water contents (Van Eaton et al. 2012a).

The size distribution of individual particles inside aggregates mimics to some degree the size distribution of the parent deposit and the sorting related to the specific emplacement mechanism (i.e., fallout or PDC). Analyzing the distribution of aggregates within different deposit types at Laacher See, Schumacher and Schmincke (1995) observed that aggregates within co-ignimbrite fall deposits showed a unimodal distribution of particles with maximum grain sizes between 250 and $350 \mu \mathrm{m}$, while aggregates within PDC deposits from hydromagmatic activity (i.e., pyroclastic surge) had coarser modes at $>500 \mu \mathrm{m}$, in rare cases up to $2 \mathrm{~mm}$. The occurrence of aggregates with a nucleus $>500 \mu \mathrm{m}$ found at distal sites from the vent was attributed to the increase in water vapor condensation during the horizontal spreading of PDCs, causing the greater amounts of water available to accrete coarser particles (Schumacher and Schmincke 1995).

\section{Aggregates at El Chichón (Mexico) and Ilamatepec (EI Salvador) volcanoes}

Several types of aggregates (irregular clusters, spherical or elongated pellets, with or without a concentric lamination or a solid nucleus, following Brown et al. 2012), consisting of crystals and pumice clasts and cemented by a film rich in $\mathrm{S}$ and $\mathrm{Fe}$, were found in deposits emplaced by PDCs of the 1982 eruption of El Chichón (Mexico) (Scolamacchia et al. 2005) (Fig. 2a, b) and the 2005 eruption of Ilamatepec (El Salvador) (Scolamacchia et al. 2010).

Such aggregates are only sometimes visible at the outcrop scale at both volcanoes, due to their covering of fine ash. Nevertheless, after being cleaned with an ultrasonic device (see Scolamacchia et al. 2005 for analytical methods used), such aggregates represent a significant fraction (30 up to $90 \%$ ) of the components of deposits produced during several eruptive phases by hydromagmatic activity of El Chichón. Individual particles in all aggregates have median grain sizes between 250 and $63 \mu \mathrm{m}$, reflecting the median granulometric distribution of the host deposits, but $2-3 \mathrm{wt} \%$ of particles of 2-6 $\mathrm{mm}$ in size not only functions as nuclei for the accretion of other particles, but also occurs in rims of pellets with a concentric structure (e.g., Figs. 8A, B of Scolamacchia et al. 2005). These finer-grained rims are composed of particles $<63 \mu \mathrm{m}$ (88 to $95 \mathrm{wt} \%$ ), most of which (74-78 wt \%) are finer than $16 \mu \mathrm{m}$ (as observed in other aggregates worldwide). They also contain abundant particles with sizes of $125 \mu \mathrm{m}$ (14 to $21 \mathrm{wt} \%), 250 \mu \mathrm{m}(9-11 \mathrm{wt} \%)$, and $500 \mu \mathrm{m}(4-6 \mathrm{wt} \%)$. In irregular clusters, particles between $500 \mu \mathrm{m}$ and $3 \mathrm{~mm}$ represent between 40 and $60 \mathrm{wt} \%$ of the individual components. All particles are strongly bound to each other with a redorange film (Fig. 2a, b), conferring an overall poor sorting of the aggregate (Fig. 3a, b). Strongly cemented irregular clusters, able to survive vigorous sieving by hand, represent up to $90 \mathrm{wt} \%$ of fractions $>4 \mathrm{~mm}$ in some deposits. The distribution of all types of cemented aggregates shows greater abundance in proximal-medial areas (4-6 km from the crater) even if they are still present in smaller amounts $(<10 \mathrm{wt} \%)$ up to $9 \mathrm{~km}$ (Scolamacchia et al. 2005). Beyond these distances, aggregates consist only of structureless pellets (AP1 of Brown et al. 2012), which are free of the S-rich film, and consist mostly of particles finer than $16 \mu \mathrm{m}(50$ to $85 \mathrm{wt} \%)$ with maximum sizes of individual components of $100-300 \mu \mathrm{m}$ (similar to 

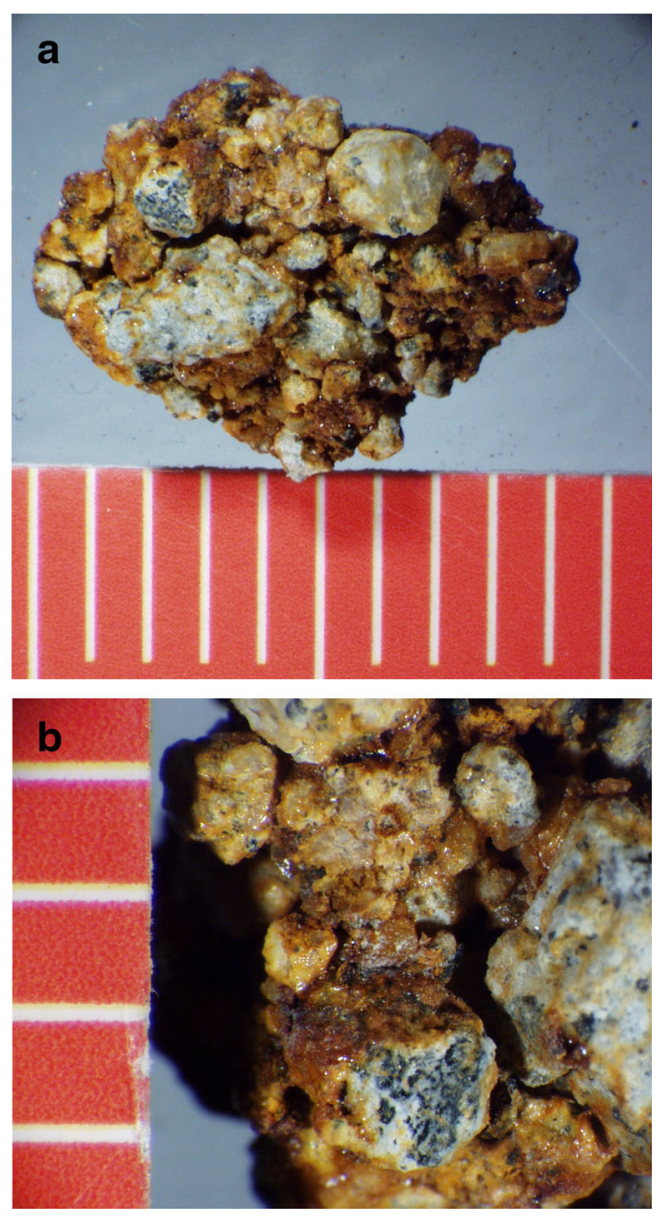

Fig. 2 a View of an irregular cluster found in the 1982 PDC deposits at El Chichón volcano. Note the red cementing film among particles, consisting of crystals of different types and rounded pumice. Scale at the bottom in millimeter. b Detail of the film cementing particles in irregular clusters at El Chichón. Note the thickness of the film and the maximum sizes of particles, which commonly exceed $1 \mathrm{~mm}$. Scale to the left in millimeter

aggregates described in other fallout and co-PDC deposits worldwide, e.g., Schumacher and Schmincke 1991; Bonadonna et al. 2002; Brown et al. 2010; Van Eaton and Wilson 2013). These pellets, which are also found associated with different types of cemented aggregates at lesser distances from the vent (i.e., Table 1 of Scolamacchia et al. 2005), have been inferred to have settled from phoenix clouds associated with PDC movement up to distances of $10.5 \mathrm{~km}$ (the maximum extension of diluted PDC deposits at El Chichón).

Cemented aggregates have also been found in PDC deposits of the 2005 eruption of Ilamatepec (mostly coated particles or pellets with a concentric structure, PC2 and AP2 of Brown et al. 2012), in which case, they represent more than $50 \mathrm{wt} \%$, sometimes up to $90 \mathrm{wt} \%$, of size fractions between 8 and $2 \mathrm{~mm}$, with a distribution limited to distances up to $5 \mathrm{~km}$ from the eruptive vent (Scolamacchia et al. 2010). Scolamacchia et al. (2005) interpreted the nature of the S-Fe-rich film binding the particles to the precipitation of an
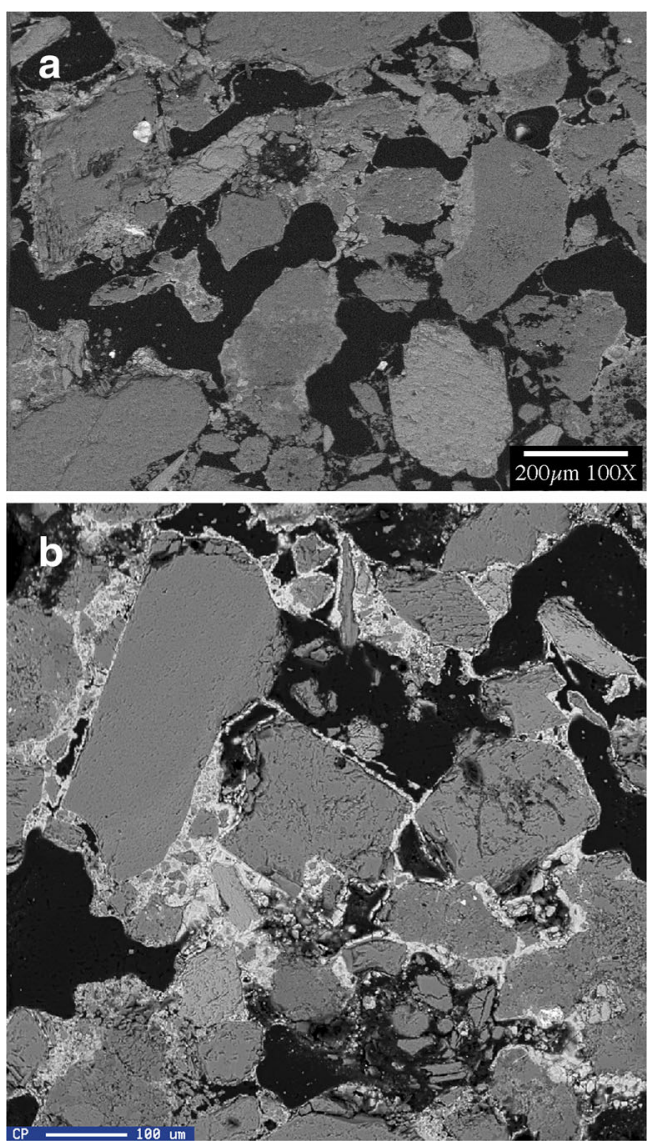

Fig. 3 a Backscattered SEM image showing the contact between single particles in ash aggregates found at El Chichón. Note the poor sorting, coarser fragments, and abundant void spaces among particles, constituting the aggregate. A micrometric-thick film (white), exhibiting bubblelike shapes, holds the particles together. Compare with Fig. 4. b Backscattered SEM image showing a detail of the cementing film between different particles, mostly crystals of plagioclase, in ash aggregates found at El Chichón. The high contrast of the film, few microns thick, is due to its high $\mathrm{Fe}$ content, as well as $\mathrm{S}$

amorphous phase from either S-rich solutions or condensing hygroscopic fluids, derived from the contemporaneous ejection of magmatic, hydrothermal fluids and phreatic water during several phases of the eruption.

\section{Microanalytical investigation}

An increasing number of field and experimental studies have demonstrated that the maximum sizes of individual particles accreted in aggregates are much smaller than those found in aggregates found at El Chichón and Ilamatepec (see Background section). Moreover, the amount of water uptake on ash surfaces due to hygroscopic soluble salts or aerosols does not increase except for the case of high RH conditions, which has been tested only on fine ash $(<125 \mu \mathrm{m})$ (Lathem et al. 2011). Given the above gaps in our understanding of these processes, here we reinvestigate the process of accretion by analyzing 
transversal cross sections of aggregates. We used a CAMECA SX100 electron microprobe (LMU Munich) with an accelerating potential of $15 \mathrm{kV}$ and a beam current of $5 \mathrm{nA}$.

In spherical and elongated pellets with a concentric structure, the cementing film was less than $1 \mu \mathrm{m}$ thick and distributed within the fine-grained material (see Fig. 9E, F of Scolamacchia et al. 2005), preventing quantitative measurement by WDS.

In irregular clusters and in spherical pellets with a solid core, the film thickness was up to 5-6 $\mu \mathrm{m}$. In this case, even when using a focused beam (100-200 nm), the beam thickness was $6-8 \mu \mathrm{m}$; therefore, a contamination from neighboring particles is expected. The contact between the film and the accreted particles (Fig. 4a, b) indicates that some of them (i.e., pumice) were still molten and mingled with the cementing material (Fig. 4b). Reaction rims/fronts occur between the film and the crystals (Fig. 4b), and an incipient vesiculation of the film between accreted glass and crystals is visible (Fig. 4a, b). Therefore, it is likely that the composition of the film is not the original one. Chips of crystals resulting from fracturing along preexisting inclusions (see Scolamacchia et al. 2005) are preserved by the film close to the locus of rupture (Fig. 4b). These textural features indicate that the accretion occurred during the early stages of particle ejection, before they were cooled in the atmosphere.

\section{Evidence of other aggregation regimes: sulfur as a binder}

The common occurrence of individual components larger than $1 \mathrm{~mm}$ in aggregates of El Chichón and Ilamatepec volcanoes contrasts with the size of individual particles inside aggregates found in different types of pyroclastic deposits worldwide, where clasts $>500 \mu \mathrm{m}$ are only found as nuclei for the accretion of smaller ones (Schumacher and Schmincke 1995).

Nevertheless, individual components exceeding $850 \mu \mathrm{m}$, in many cases $1.4 \mathrm{~mm}$, have been reported in aggregates of different shapes (i.e., irregular, elongated, or spherical) found on sulfur cones formed inside the crater of Poás volcano in 1989 (Oppenheimer 1992). Such aggregates had an overall poor internal sorting. Spherical aggregates up to $5 \mathrm{~cm}$ displayed, in some cases, a weak internal layering. Such aggregates could have formed within the conduits of sulfur cones, during eruptions consisting of "geyser-like" bursts of mud and liquid sulfur up to heights of $5 \mathrm{~m}$, at rates $1 / \mathrm{s}$, attributed to the venting of fumarolic gases toward the surface through shallow layers of molten sulfur, whereby the individual components were cemented by liquid sulfur derived from the remelting of S-grains (Oppenheimer 1992). Oppenheimer and Stevenson (1989) attributed the accumulation of layers of elemental sulfur $\left(\mathrm{S}_{\mathrm{e}}\right)$ to the reactions occurred between ascending $\mathrm{SO}_{2}$ and $\mathrm{H}_{2} \mathrm{~S}$ (either $\mathrm{SO}_{2}$ disproportionation or, oxidation of $\mathrm{H}_{2} \mathrm{~S}$ by $\mathrm{SO}_{2}, \mathrm{O}_{2}, \mathrm{H}_{2} \mathrm{O}, \mathrm{H}_{2} \mathrm{SO}_{4}$, or $\mathrm{Fe}^{3+}$ contained in the lake waters) from a degassing andesitic magma at shallow
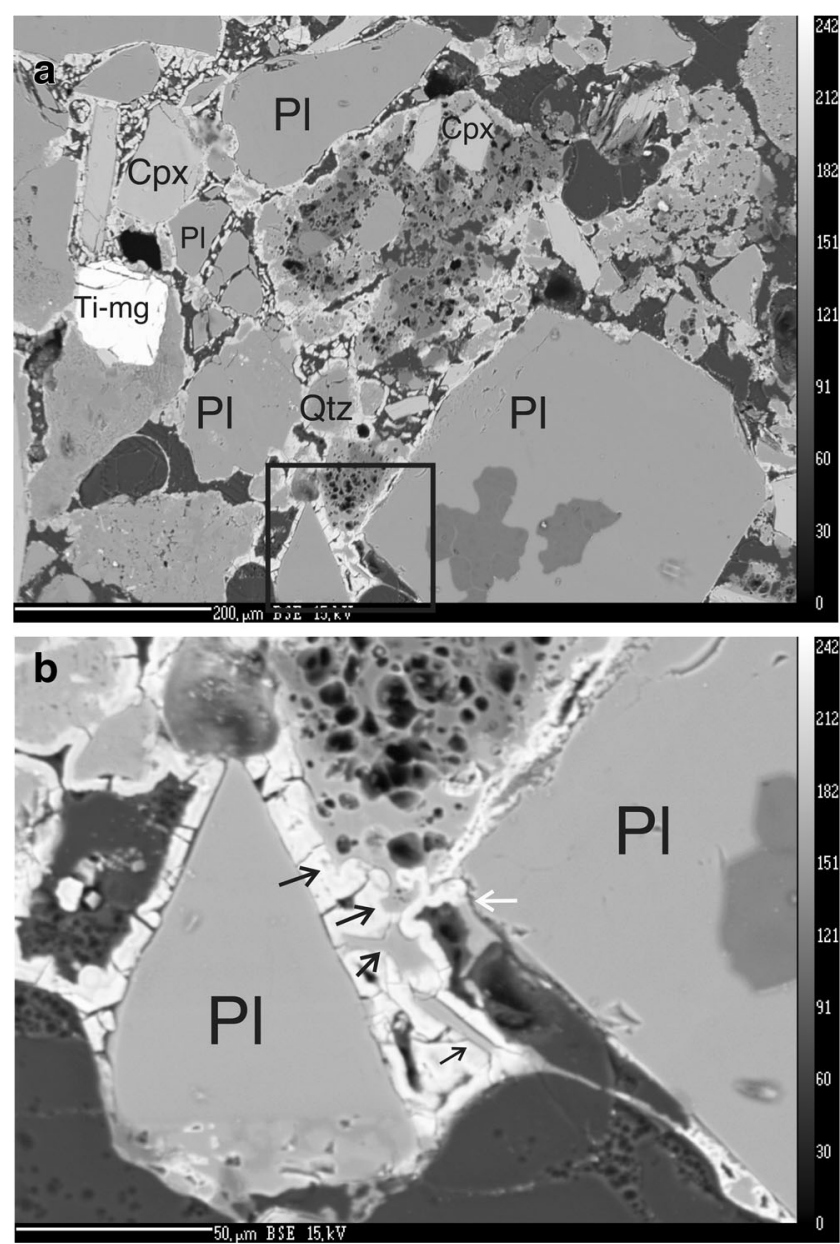

Fig. 4 a Backscattered SEM image of a cross section of a spherical pellet around a solid core, found at distance of $3.7 \mathrm{~km}$ to the East of the crater at El Chichón. The high-density (white) film bounds particles together. The irregular borders of some of the crystals are likely the result of their fracturing along preexisting glass inclusions. The cemented film penetrates some of the fractured crystals (e.g., plagioclase crystal fractured in three parts on the upper left of the photo, above the Ti-magnetite). A pumice is "squeezed" and bounded to nearby crystals. The black square indicates a portion described in detail in Fig. 4b. b View of the contact between the lower part of the pumice and the film cementing it to the nearby crystals. Note the irregular pumice borders along the film (left) and the mingling of the glass with the cementing film (lower part of the photo), indicated by the black arrow. The cementing film between the pumice and the plagioclase crystal on the right shows signs of an incipient vesiculation. Note that a portion of the crystal on the right is detached from the main body of the crystal, following fracturing along a set of inclusions, but it is hold by the cementing film (white arrow). The lower portion of the crystal on the left shows signs of reactions with the highdensity film, and the inclusions migrate toward the central portion of the crystal (see text for discussion)

depths and the lake sediments. Sulfur melting would have occurred after that the lake waters, which were acting as a temperature buffer, disappeared, allowing the sediment interface temperature to rise above the sulfur liquidus. The low viscosity of $\mathrm{S}$ at temperatures near its melting temperature would have facilitated its migration and coalescence with sediments (Oppenheimer 1992). 
The similarities (i.e., internal grain-size distribution, sorting, morphology, and composition of the cementing film) between the sulfur aggregates described at Poás (Oppenheimer 1992) and those reported at El Chichón and Ilamatepec indicate that, also in these cases, sulfur acted as a binder among particles. Nevertheless, in contrast to Poás, the pristine composition of the binding substance of aggregates described here cannot be determined and reflects the sum of different contamination processes, which are difficult to separate due to the peculiar behavior of sulfur (see Discussion section).

The abundance of such aggregates in deposits emplaced during different phases of the 1982 eruption of El Chichón (right up to the final ones) indicates that liquid sulfur was explosively ejected and that its supply was sustained. Moreover, the poor internal sorting (Figs. 2a and 3a), and their textural features (Fig. 4a, b), suggests a fast process of accretion, completed before pumice cooling and before the fragments from fractured crystals were separated, in contrast with respect to those described elsewhere (Fig. 5).

\section{Evidence of S-layers}

The explosive ejection of liquid sulfur is not unusual and has been reported at other andesitic volcanoes hosting hydrothermal systems, beside Poás. At Kusatsu-Shirane (Japan), the ejection of liquid $\mathrm{S}$ occurred during several phreatic eruptions, through the acidic lake inside the crater (Takano et al. 1994). At Ruapehu, the most active volcano of New Zealand, the accumulation of a pool of elemental sulfur $(>50 \mathrm{~m}$ in diameter and $6 \mathrm{~m}$ deep), with temperatures between 173 and $177{ }^{\circ} \mathrm{C}$, was discovered in 1991 at depths of $134 \mathrm{~m}$ beneath a hot, acidic lake hosting sulfate-chloride waters (Crater Lake) inside the crater (Christenson and Wood 1993). Historical activity consisted mostly of phreatic and phreatomagmatic eruptions, with the occurrence of few Plinian eruptions, and the effusive emplacement of viscous andesitic lava domes (Johnston et al. 2000). According to the model of hydrothermal system envisaged at Ruapehu (Hurst et al. 1991; Christenson and Wood 1993; Christenson 2000), the condensation of more soluble gases $\left(\mathrm{SO}_{2}\right.$ and $\left.\mathrm{H}_{2} \mathrm{~S}\right)$ among those exsolved from an andesitic magma reacts with water-saturated sediments, within a convective hydrothermal system, precipitating native sulfur $\left(\mathrm{S}_{\mathrm{e}}\right)$ through the reaction $2 \mathrm{H}_{2} \mathrm{~S}+\mathrm{SO}_{2}=3 \mathrm{~S}_{\mathrm{e}}+\mathrm{H}_{2} \mathrm{O}$ (Christenson 2000). Such process would have caused the deposition of shrouds of elemental S around the conduits and an S-pool at the lake bottom, in a time lapse between 20 and 50 years following major magmatic eruptions, in 1945 and 1995-1996, despite the occurrence of phreatic and phreatomagmatic eruptions (Christenson 2000; Christenson et al. 2010). Modeling by Christenson and Woods (1993) of hydrothermal circulation before the 1995-1996 eruption

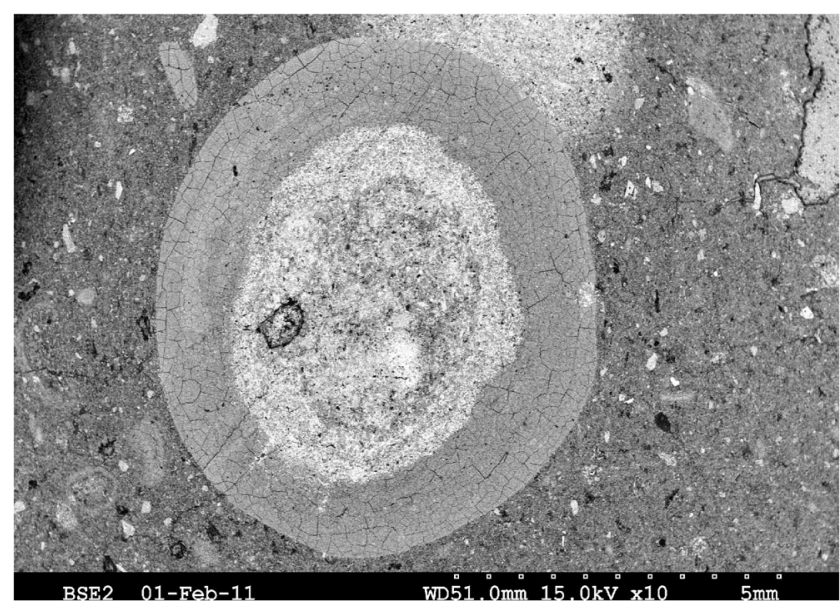

Fig. 5 Backscattered SEM image of a 7-mm pellet with concentric structure found embedded in the Poris ignimbrite, Tenerife. Note the finer-grained size and better internal sorting of both the structurelesscore and the fine-grained rim, compared to aggregates found at El Chichón. Image courtesy of E. McGowan and M. Branney

indicated that the condensation of $1 \mathrm{~kg}$ of magmatic gases at $250^{\circ} \mathrm{C}$ and $0.85 \mathrm{MPa}$ would have determined the precipitation of $10 \mathrm{~g}$ of elemental $\mathrm{S}$ followed by the precipitation of anhydrite and alunite. Christenson (2000) estimated that $0.75 \mathrm{Tg}$ of elemental $\mathrm{S}$ was introduced in the hydrothermal system between 1967 and 1995; assuming an average input of $30 \mathrm{Gg}$ per year after 1945, a total amount of $1.5 \mathrm{Tg}$ was stored in the hydrothermal system in 1995. Apparently, this amount was expelled during this eruption.

Similarly, Rowe et al. (1992) estimated deposition of $1.15 \times 10^{7} \mathrm{~kg} \mathrm{~S} /$ year in the hydrothermal system of Poás volcano.

Even if the storage of layers of elemental sulfur was not reported at El Chichón volcano, several lines of evidence support this hypothesis.

The 1982 eruption breached through a sealed hydrothermal system (Taran et al. 2008), uncovering its upper $500 \mathrm{~m}$, forming a $1-\mathrm{km}$ wide and 300-m deep crater (Taran et al. 1998), and releasing 5-9 $\mathrm{Tg}$ of $\mathrm{SO}_{2}$ in the stratosphere (Krueger et al. 1995), 7.5 $\mathrm{Tg}$ of $\mathrm{SO}_{2}$ according to more recent estimates (Krueger et al. 2008).

Sulfur content in fresh pumices was estimated in $\approx 1.25 \mathrm{wt} \% \mathrm{SO}_{3}$, almost entirely in the form of $\approx 1 \mathrm{vol} \%$ anhydrite crystals precipitated directly from a trachyandesitic magma at temperatures of $810 \pm 40{ }^{\circ} \mathrm{C}$, as attested by both $\delta^{34} \mathrm{~S}$ and $\delta^{18} \mathrm{O}$ isotopic data (Rye et al. 1984) and textural evidences (Luhr et al. 1984; Luhr and Logan 2002). The total content of sulfur in magma, estimated in $2.6 \mathrm{wt} \% \mathrm{SO}_{3}$, was nearly an order of magnitude greater than contents typical for subduction-related magmas (Luhr et al. 1984; Varekamp et al. 1984).

The 1982 pumice consisted of a stable equilibrium assemblage of hornblende, augite, pyrrhotite, anhydrite, and 
titanomagnetite (Luhr et al. 1984). Anhydrite microcrystals account for $1.3 \mathrm{wt} \%$ of the total $\mathrm{S}$ emitted. Nevertheless, the low $\mathrm{S}$ content $(<0.1 \mathrm{wt} \%)$ in the matrix glass of the 1982 pumices and evidence from trapped glass inclusions both suggest that the remaining $1.2 \mathrm{wt} \%$ was present in a separate gas phase, in which the fugacity of $\mathrm{H}_{2} \mathrm{~S}$ was greater than $\mathrm{SO}_{2}$ (Luhr et al. 1984). This hypothesis is consistent with the high $\delta^{34} \mathrm{~S}$ values $(5.8 \%$ ) estimated for the bulk magma (i.e., melt, crystals, and gas), suggesting a loss of $\mathrm{H}_{2} \mathrm{~S}$ depleted in ${ }^{34} \mathrm{~S}$, into a liquid or a gas phase at depth (Rye et al. 1984). Beside primary anhydrite in juvenile material, lithic clasts ejected during the eruption showed intense sulfide mineralization and anhydrite veins, with isotopic values of $\delta^{34} \mathrm{~S}=13.3 \%$. These isotopic values were explained with the presence of heavy hydrothermal components beneath El Chichón (Rye et al. 1984).

Varekamp et al. (1984) and Luhr et al. (1984) have suggested that almost all sulfur not present as microphenocrysts of anhydrite was released as a $\mathrm{H}_{2} \mathrm{~S}$ gas inside the eruptive clouds and then either absorbed onto ash after its oxidation to sulfate or alternatively condensed as sulfuric acid droplets, leading to a clustering of fines $(<63 \mu \mathrm{m})$ and producing a polymodal distribution (with modes at 4 and $1 \mathrm{~mm}$ ) of fallout at distances of 17, 22, and $110 \mathrm{~km} \mathrm{NE}$ from the vent. Both $\delta^{18} \mathrm{O}$ and $\delta^{34} \mathrm{~S}$ isotopic data indicate that the rapid oxidation of $\mathrm{H}_{2} \mathrm{~S}$ into $\mathrm{SO}_{4}{ }^{2-}$ into eruptive clouds was kinetically prohibited and that a more likely source of sulfate adsorbed on ash consisted of primary oxidized sulfur (Rye et al. 1984). The lower isotopic values of oxygen and sulfur of the bulk ash leachates $\left(\delta^{34} \mathrm{~S}=+7.8\right.$ to $8.4 \%$ ), compared with those of anhydrites crystals in pumices, suggested that the excess $\mathrm{S}$ did not derive from the dissolution of primary anhydrite (Rye et al. 1984). Varekamp et al. (1984) indicated that using only the main phases occurring in pumices to obtain the modal composition of ashes always yielded negative quantities of augite by including excess $\mathrm{Na}$ and $\mathrm{S}$ as plagioclase and anhydrite. Nevertheless, the fits improved when additional Na-K-rich phases (accounting for vapor phase condensates and altered lithic fragments rich in alkalis), and elemental S (accounting for sulfur not present as anhydrite), were included. Pyrite and anhydrite, found in accidental blocks ejected during the 1982 eruption, were also common minerals precipitated from hydrothermal solutions at Ruapehu.

Therefore, it is likely that elemental sulfur was slowly accumulating also in the hydrothermal system at El Chichón, by precipitation from condensing $\mathrm{SO}_{2}$ and $\mathrm{H}_{2} \mathrm{~S}$, emitted from the degassing trachyandesitic magma, similar to what reported at other andesitic volcanoes hosting active hydrothermal systems (e.g., Oppenheimer and Stevenson 1989; Christenson and Wood 1993; Takano et al. 1994; Christenson 2000; Christenson et al. 2010).

In fact, Mülliered (1932) had described the presence of stalactites of native sulfur near fumaroles discharging $\mathrm{H}_{2} \mathrm{~S}$ in
1932, 50 years before the 1982 eruption, similar to the timescale invoked by Christenson et al. (2010) for the formation of a pool of elemental sulfur below Crater Lake at Ruapehu.

The thermal activity before 1982 consisted of fumaroles, hot springs, $\mathrm{H}_{2} \mathrm{~S}$ emissions, and acid-sulfate alteration concentrated around and on the flanks of a central dome plugging a Somma crater (Mülliered 1932; Molina Berbeyer 1974; Templos et al. 1981), formed after an eruption occurred approximately 500 years BP (Macías et al. 2003). These manifestations were considered consistent with the existence of a hot-water hydrothermal system overlain by a relatively small volume, vapor-dominated cap (Casadevall et al. 1984; Rye et al. 1984). Most geothermal manifestations are still present today. According to Taran et al. (1998), the springs on the southern slopes of the volcano were only minor affected by the 1982 eruption. The steaming vents and hot springs described at the base of the dome plugging the Somma crater before the 1982 eruption eventually represented the top of the steam cap of the hydrothermal system (Taran et al. 2008; Taran and Peiffer 2009).

As observed at other volcanoes hosting active hydrothermal systems, El Chichón experienced a very fast transition from magmatic to hydrothermal stage following the 1982 eruption (Casadevall et al. 1984; Peiffer et al. 2011). The formation of a lake inside the crater occurred shortly after the end of the eruption, in late April 1982, and was attributed to a refilling by groundwaters (Casadevall et al. 1984), with a minor contribution by rainfall. The salinity and volume of the lake has changed considerably with time due to a group of geyser-like boiling springs, inside the crater (Soap Pools of Taran et al. 1998). The springs discharge clear highly saline (TDS $>20,000 \mathrm{mg} / \mathrm{kg}$ ) boiling Na-Ca-Cl waters, with a periodic behavior (Taran et al. 2008; Rouwet et al. 2008) in which vapor exhalations, with periods of few months to 1 year, alternate with periods of discharge of near-neutral Cl-rich waters that directly feed the lake at rates between 10 and 30 1/s (Taran and Rouwet 2008). The composition of these Soap Pool springs (currently $3,000 \pm 1,000 \mathrm{mg} / \mathrm{l}$ of Cl) has been linked to a group of springs located on the SE and SW flanks, and $\mathrm{Sr}$ isotopes and $\mathrm{Ca} / \mathrm{Sr}$ ratios suggest that all of them are fed by a shallow volcanic aquifer located at depths of $280 \mathrm{~m}$ beneath the crater, with a maximum horizontal extension of $3.5 \mathrm{~km}$ (Peiffer et al. 2011).

The hydrology of El Chichón suggests that before the 1982 eruption, this shallower aquifer acted as a lake condensing previous rising gases.

According to Taran et al. (1998), the Cl-rich waters of the SP springs represent condensed magmatic vapor neutralized by the interaction with fresh deposits and depleted in $\mathrm{S}$ due to anhydrite precipitation. Also, the low sulfur content in the lake waters at El Chichón, and fumarolic gases, after the 1982 eruption, was attributed to a loss of sulfur at depth with the formation of anhydrite or alunite (Taran et al. 1998). 
Nevertheless, considering the mechanisms that lead to the deposition of elemental S at Ruapehu, the low S contents of the SP springs, and the lake waters, could be also explained with the precipitation of elemental $\mathrm{S}$ at depth, as envisaged at Ruapehu and Poás volcanoes. This process may have occurred also before the 1982, leading to the formation of layer(s) of elemental S.

The occurrence of a similar cementing film in aggregates found in PDC deposits emplaced during the 2005 eruption of Ilamatepec volcano (El Salvador) (Scolamacchia et al. 2010) suggests that also during this eruption, liquid sulfur was explosively ejected. In fact, a vapor-dominated hydrothermal system is inferred to exist at low depths beneath the acid lake (Bernard et al. 2004).

\section{Discussion}

According to all experimental results to date (Gilbert and Lane 1994; Schumacher and Schmincke 1995; James et al. 2002; Van Eaton et al. 2012a), aggregation processes are strongly particle size dependent. Yet, the validity of such a conclusion may only apply when considering water or electrostatic attraction as binding agents between particles. Different experimental results agree in the existence of a lower limit around $15 \mathrm{wt} \%$ liquid water for the formation of stable spherical aggregates and an upper limit of $25 \mathrm{wt} \%$, after which the aggregates began to clot. Under these conditions, the scavenging of particles of different sizes is controlled by liquid water contents, but particles $>1 \mathrm{~mm}$ are rarely accreted, unless as nucleation sites (i.e., cores) for sticking smaller particles; in addition, capillary forces are ineffective for high amounts of liquid water ( $>25 \mathrm{wt} \% ;>50 \mathrm{vol} \%)$, for which the formation of stable aggregates is prevented for any particle size (Schumacher and Schmincke 1995; Van Eaton et al. 2012a, b).

Particles larger than $1 \mathrm{~mm}$ are instead common inside aggregates found at Poás, El Chichón, and Ilamatepec volcanoes; at El Chichón and Ilamatepec, they occur also in the most external rims, which are instead characteristically made of particles only tens of microns in size in pellets formed by the binding action of water.

Such evidence indicates that liquid sulfur is able to remove coarser particles (i.e., size of lapilli) from the eruptive clouds, with respect to those (tens to hundreds $\mu \mathrm{m}$ ) removed by either water bridges or electrostatic attraction, as suggested by observations and experimental studies (see Background section).

Such a binding property would depend on sulfur viscosity. Sulfur viscosity is highly temperature dependent, varying from $0.01 \mathrm{~Pa} \mathrm{~s}$ around its melting point $\left(116.3{ }^{\circ} \mathrm{C}\right.$, for its triclinic modification according to Cernosek et al. 2009) to values up to 3 orders of magnitude greater at $160{ }^{\circ} \mathrm{C}$ due to polymerization (Meyer 1976; Sagan 1979). At Poás, the temperature of ejected sulfur during S-eruptions in 1989 was
$96.7{ }^{\circ} \mathrm{C}$ near the vents of sulfur cones and $55^{\circ} \mathrm{C}$ on their flanks. Direct measurements of sulfur lakes established within the craters of sulfur cones after the eruptions ceased yielded values of $116^{\circ} \mathrm{C}$, but temperatures up to $159^{\circ} \mathrm{C}$ were measured in one of them in 1990 (Oppenheimer 1992).

Nevertheless, sulfur properties depend on its thermal history and its potentially metastable state (Meyer 1964, 1976; Sagan 1979; Cernosek et al. 2009). Meyer (1976) reported at least 19 different melting points for elemental sulfur (i.e., 94 to $133^{\circ} \mathrm{C}$ ), which were explained by the slow kinetics of the melting process and the different reaction paths followed on cooling (resulting in various metastable mixtures of different metastable allotropes). S-allotropes can form, or transform, under the influence of minor disturbances, such as sunlight, recrystallization, and time alone. Moreover, experimental determination of the S-phase composition evidenced that during sample preparation, a variety of allotropes formed and coprecipitate with sulfides, oxyacids, and solvents. The viscosity of sulfur around its (variable) melting point is ten times the viscosity of water at $20^{\circ} \mathrm{C}$ (Sagan 1979). This much higher viscosity than water can explain both its capacity to accrete coarser particles and to cement them. Sulfur is therefore able to provide stronger bonds with respect to water, considered to date the strongest binding substance among particles of aggregates in pyroclastic deposits (Brown et al. 2012 and references therein).

The formation of sulfur layers of different spatial extent has been reported at several volcanoes with active hydrothermal systems, and this work infers a similar process at El Chichón and Ilamatepec volcanoes. All volcanoes show a common eruptive pattern, in which periods of frequent phreatic and phreatomagmatic events through a crater lake are followed by rare periods of effusive dome growth or explosive magmatic activity.

All these cases suggest that the storage of sulfur layers in andesitic volcanoes hosting active hydrothermal systems may be more common than previously assumed.

\section{Concluding remarks and suggestions for further work}

The poor internal sorting of particles inside aggregates described at El Chichón and Ilamatepec volcanoes suggests a faster process of accretion with respect to those described elsewhere. Such a hypothesis is confirmed by the textural features observed inside cemented aggregates, which attest that some particles were still molten at the moment of accretion, and by the distribution of the aggregates, limited to distances of few kilometers from the eruptive vents, in contrast to aggregates described elsewhere (tens to hundreds of $\mathrm{km}$ ). Such distribution suggests that when explosively ejected, sulfur is able to cause the settling of coarser particles $(>2 \mathrm{~mm})$ from eruptive clouds, already at distances of few 
kilometers from eruptive vents and eventually at lower atmospheric levels, compared to what was commonly thought. In contrast to what observed in sulfur eruptions at Poás, the aggregates described here were likely transported at greater distances with respect to their locus of formation, by turbulent PDCs, in which aggregates are found.

Such evidence has important implications on the volumetric estimates of different grain sizes inside eruptive clouds and should be considered in models of particle dispersion and sedimentation to improve hazard assessment.

The maximum dimensions, the shape, and the internal structure of aggregates found at El Chichón and Ilamatepec are similar to those of aggregates formed by the binding action of water. The only differences are the maximum grain size of individual particles accreted and the presence of a film cementing the grains. Such characteristics are not visible at the outcrop scale, but only apparent after the ultrasonic cleaning of samples (Scolamacchia et al. 2005). Considering that the accumulation of sulfur layers has been described at several volcanoes hosting hydrothermal systems, it is probable that aggregates similar to those described here also occurred in other PDC deposits but were not properly recognized because of the lack of proper analyses. Future work should concentrate on their identification, characterization, and spatial distribution in order to provide an adequate basis for modeling.

Due to the intrinsic complexity of the state of sulfur, the minimum amount necessary to stick particles of different sizes is difficult to estimate and likely represent the sum of different processes, especially when its ejection is contemporaneous with that of other fluids (e.g., hydrothermal). As suggested by textural features of aggregates showed here, eventually liquid $\mathrm{S}$ continued to react with nearby crystals and glass accreted. Previous studies indicate that the cooling of molten $\mathrm{S}$ involves different reaction paths, producing a range of metastable allotrope mixtures, and due to the high heat capacity of S-melts, the isolation of impurities is difficult (Meyer 1976). Experimental efforts should concentrate in finding solutions to determine the optimum amount of S necessary to accrete particles of different sizes.

The settling velocity of aggregates is considered to be lower than that of single particles, due to the presence of lighter fluids (air or water). Notwithstanding the fact that the bulk densities of sulfur aggregates reported by Oppenheimer (1992) at Poás range between 900 and $1,500 \mathrm{~kg} / \mathrm{m}^{3}$, similar to those reported for aggregates elsewhere $(1,200$ $1,600 \mathrm{~kg} / \mathrm{m}^{3}$, Brown et al. 2012), the variations in density and porosity of aggregates with respect to single particles in the presence of $\mathrm{S}$ need experimental investigation. In fact, the density of solid elemental sulfur is higher than water (i.e., in a range between 1.92 and $2.07 \mathrm{~g} / \mathrm{cm}^{3}$ depending on the allotrope), and the presence of other elements, as impurities (e.g., Fe), could contribute to an increase in the density of the binding material.
Acknowledgments This research was supported by the ERC Advanced Researcher Grant "EVOKES" (247076) to DBD. TS acknowledges a Marie Curie International Reintegration Grant "SPAEx" (239259). Revisions by Alexa Van Eaton and editorial handling of Clive Oppenheimer improved the quality of this manuscript.

\section{References}

Bernard A, Escobar CD, Mazot A, Gutierrez RE (2004) The acid volcanic lake of Santa Ana volcano, El Salvador. In: Rose WI, Bommer JJ, López DL, Carr MJ, Major, JJ (ed) Natural hazards in El Salvador. Geol Soc Am Spec Pap, pp 121-133

Bonadonna C, Maybery GC, Calder ES, Sparks RSJ, Choux C, Jackson Lejeune AM, Loughlin SC, Norton GE, Rose WI, Ryan G, Young SR (2002) Tephra fallout in the eruption of Soufriére Hills Volcano, Montserrat. In: TH Druitt, Kokelaar B (eds) The eruption of Soufriére Hills Volcano, Montserrat from 1995 to 1999. Geological Society of London Memoir, pp. 483-516

Branney MJ, Brown RJ (2011) Impactoclastic density current emplacement of terrestrial meteorite-impact ejecta and the formation of dust pellets and accretionary lapilli: evidence from Stac Fada, Scotland. J Geol 119:275-292. doi:10.1086/659147

Brazier S, Davis AN, Sigurdsson H, Sparks RSJ (1982) Fall-out and deposition of volcanic ash during the 1979 explosive eruption of the Soufriére of St. Vincent. J Volcanol Geotherm Res 14:335-359

Brazier S, Sparks RSJ, Carey SN, Sigurdsson H, Westgate JA (1983) Bimodal size distribution and secondary thickening in air fall layers. Nature 301:115-119

Brown RJ, Branney MJ, Maher C, Dávila-Harris P (2010) Origin of accretionary lapilli within ground-hugging density currents: evidence from pyroclastic couplets on Tenerife. Geol Soc Am Bull 122(1/2):305-320. doi:10.1130/B26449.1

Brown RJ, Bonadonna C, Durant AJ (2012) A review of volcanic ash aggregation. Phys Chem Earth A/B/C 45-46:65-78

Carey SN, Sigurdsson H (1982) Influence of particle aggregation on deposition of distal tephra from the May 18, 1980 eruption of Mount St. Helens' volcano. J Geophys Res 87(B8):7061-7072

Casadevall TJ, De la Cruz-Reyna S, Rose WI, Bagley S, Finnegan DL, Zoller WH (1984) Crater lake and post-eruption hydrothermal activity, El Chichón Volcano, Mexico. J Volcanol Geotherm Res 23: 169-191

Cernosek Z, Holubova E, Cernoskova E, Ruzicka A (2009) Sulfur-a new information on this seemingly well-known element. J Nonoxide Glas 1(1):38-42

Christenson BW (2000) Geochemistry of fluids associated with the 1995-1996 eruption of Mt. Ruapehu, New Zealand: signatures and processes in the magmatic-hydrothermal system. J Volcanol Geotherm Res 97:1-30

Christenson B, Wood CP (1993) Evolution of a vent-hosted hydrothermal system beneath Ruapehu Crater Lake, New Zealand. Bull Volcanol 55:547-565

Christenson BW, Reyes AG, Young R, Moebis A, Sherburn S, ColeBaker J, Britten K (2010) Cyclic processes and factors leading to phreatic eruption events: insights from the 25 September 2007 eruption through Ruapehu Crater Lake, New Zealand. J Volcanol Geotherm Res 191:15-32

Costa A, Folch A, Macedonio G (2010) A model for wet aggregation in volcanic plumes and clouds: 1 . Theoretical formulation. J Geophys Res 115, B09201. doi:10.1029/2009JB007175

Durant AJ, Shaw RA, Rose WI, Mi Y, Ernst GGJ (2008) Ice nucleation and overseeding of ice in volcanic clouds. J Geophys Res 113, D09206. doi:10.1029/2007JD009064 
Durant AJ, Rose WI, Sarna-Wojcicki AM, Carey S, Volentik ACM (2009) Hydrometeor-enhanced tephra sedimentation: constrains from the 18 May 1980 eruption of Mount St. Helens. J Geophys Res 114, B03204. doi:10.1029/2008JB005756

Folch A, Costa A, Durant A, Macedonio G (2010) A model for wet aggregation of ash particles in volcanic plumes and clouds: 2 . Model application. J Geophys Res 115, B09902. doi:10.1029/ 2009JB007176

Gilbert JS, Lane SJ (1994) The origin of accretionary lapilli. Bull Volcanol 56:398-411

Hobbs PV, Tuell JP, Hegg DA, Radke LF, Eltgroth MW (1982) Particles and gases in the emissions from the 1980-1981 volcanic eruptions of Mt. St. Helens. J Geophys Res 87(C12):11,062-011,086

Hobbs PV, Radke LF, Lyons JH, Ferek RJ, Coffmann DJ, Casadevall TJ (1991) Airborne measurements of particle and gas emissions from the 1990 volcanic eruptions of Mount Redoubt. Redoubt J Geophys Res 96(D10):18,735-18,752

Hurst AW, Bibby HM, Scott BJ, Mc Guinness MJ (1991) The heat source of Ruapehu Crater Lake; deductions from the energy and mass balances. J Volcanol Geotherm Res 46:1-20

James MR, Gilbert, JS, Lane SJ (2002) Experimental investigation of volcanic particles aggregation in the absence of a liquid phase. $\mathrm{J}$ Geophys Res 107 doi: 10.1029/2001JB000950

Johnston DM, Houghton BF, Neall VE, Ronana KR, Paton D (2000) Impacts of the 1945 and 1995-1996 Ruapehu eruptions, New Zealand: an example of increasing societal vulnerability. Geol Soc Am Bull 112:720-726

Krueger AJ, Walter LS, Bhartia PK, Schnetzler CC, Krotkov NA, Sprod I, Bluth GJS (1995) Volcanic sulfur dioxide measurements from the total ozone mass spectrometer instruments. J Geophys Res 100: 14057-14076

Krueger A, Krotov N, Carn S (2008) El Chichon: the genesis of volcanic sulfur dioxide monitoring from space. J Volcanol Geotherm Res 175:408-414

Lane SJ, Gilbert JS, Hilton M (1993) The aerodynamic behavior of volcanic aggregates. Bull Volcanol 55:481-488

Lathem TL, Kumar P, Nenes A, Dufek J, Sokolik IN, Trail M, Russel A (2011) Hygroscopic properties of volcanic ash. Geoph Res Lett 38: L11802

Luhr JF, Logan MAV (2002) Sulfur isotope systematics of the $1982 \mathrm{El}$ Chichón trachyandesite: a ion micropobe study. Geochim Cosmochim Acta 66(18):3303-3316

Luhr JF, Carmichael ISE, Varekamp JC (1984) The 1982 eruption of El Chichón volcano, Chiapas, Mexico: mineralogy and petrology of the anhydrite bearing pumices. J Volcanol Geotherm Res 23:69-108

Macías JL, Arce JL, Mora JC, Espíndola JM, Saucedo R, Manetti P (2003) A 500-year-old Plinian eruption at El Chichón volcano, Chiapas, Mexico: explosive volcanism linked to reheating of the magma reservoir. J Geophys Res 108(B12):2569. doi:10.1029/ 2003JB002551

Meyer B (1964) Solid allotropes of sulfur. Chem Rev 64(4):429-451

Meyer B (1976) Elemental Sulfur. Chem Rev 76(3):367-388

Molina Berbeyer R (1974) Informe preliminar geoquímico de los fluidos geotérmicos del volcán del Chichonál, Chiapas. Unpublished report. Comisión Federal de Electricidad, México. Informe 27-74. 24 p

Mülliered FKG (1932) Der Chichón, ein bischer unbegannter tätiger Vulkan im nordlichen Chiapas, Mexiko. Zeit Vulkanol XIV: 191209

Oppenheimer C (1992) Sulphur eruptions at Volcán Poás, Costa Rica. J Volcanol Geotherm Res 49:1-21

Oppenheimer C, Stevenson D (1989) Liquid sulphur lakes at Poás volcano. Nature 342:790-793

Peiffer L, Taran Y, Lounejeva E, Solis-Pichardo G, Rouwet D, BernardRomero R (2011) Tracing thermal aquifers of El Chichón volcanohydrothermal system (Mexico) with $87 \mathrm{Sr} / 86 \mathrm{Sr}, \mathrm{Ca} / \mathrm{Sr}$ and REE. J Volcanol Geotherm Res 205:55-66
Reimer TO (1983) Accretionary lapilli in volcanic ash falls: physical factors governing their formation. In: Peryt TM (ed) Coated grains. Springer Verlag, Berlin, pp 56-68

Ritchie LJ, Cole PD, Sparks RSJ (2002) Sedimentology of deposits from the pyroclastic density currents of 26 December 1997 at Soufrière Hills Volcano, Montserrat. In: Druitt TH, Kokelaar, P (ed) The eruption of Soufriére Hills Volcano, Montserrat from 1995 to 1999. Geological Society of London Memoirs, pp 435-456

Rouwet D, Taran Y, Inguaggiato S, Varley N, Santiago JA (2008) Hydrochemical dynamics of the "lake-spring" system in the crater of EL Chichón volcano (Chiapas, Mexico). J Volcanol Geotherm Res 178(2):237-248

Rowe GL Jr, Brantley SL, Fernandez M, Fernadez JF, Borgia A, Barquero J (1992) Fluid-volcano interaction in an active stratovolcano: the crater lake system of Poás volcano, Costa Rica. J Volcanol Geotherm Res 49:23-51

Rye RO, Luhr JF, Wassermann MD (1984) Sulfur and oxygen isotopic systematics of the 1982 eruptions of El Chichón volcano, Chiapas, Mexico. J Volcanol Geotherm Res 23:109-123

Sagan C (1979) Sulphur flows on Io. Nature 280:750-753

Sarna-Wojcicki AM, Shipley S, Waitt Jr B, Dzurisin D, Wood SH, Lipman PW, Mullineaux DR (1981) Areal distribution, thickness, mass, volume, and grain-size of air-fall ash from the six major eruptions of 1980. In: Lipman PW, Mullineaux DR (eds) The 1980 eruptions of Mount St. Helens, Washington. US Geological Survey Professional Paper 1250, pp 577-600

Schumacher R, Schmincke HU (1991) Internal structure and occurrence of accretionary lapilli — a case study at Laacher See Volcano. Bull Volcanol 53:612-634

Schumacher R, Schmincke HU (1995) Models for the origin of accretionary lapilli. Bull Volcanol 56:626-639

Scolamacchia T, Macías JL, Sheridan MF, Hughes SR (2005) Morphology of ash aggregates from wet pyroclastic surges of the 1982 eruption of El Chichón volcano, Mexico. Bull Volcanol 68: 171-200. doi:10.1007/s00445-005-0430-x

Scolamacchia T, Pullinger C, Caballero L, Montalvo F, Beramendi Orosco L, Gonzalez Hernández G (2010) The 2005 eruption of Ilamatepec (Santa Ana) volcano, El Salvador. J Volcanol Geotherm Res 189:291-318

Sheridan MF, Wohletz KH (1983) Origin of accretionary lapilli from the Pompeii and Avellino deposits of Vesuvius. In: Gooley R (ed) Microbeam analysis. San Francisco Press, 35-38

Sparks RSJ, Bursik M, Carey S, Gilbert J, Glaze H, Sigurdsson H, Woods A (1997) Volcanic plumes. Wiley, Chichester

Taddeucci J, Scarlato P, Monatanaro C, Cimarelli C, Del Bello E, Freda C, Andronico D, Gudmunsson MT, Dingwell DB (2011) Aggregation-dominated ash settling from the Eyjafjallajökull volcanic cloud illuminated by field and laboratory high-speed imaging. Geology 39(9):891-894

Takano B, Saito H, Takano E (1994) Geochemical implications of subaqueous molten sulfur at Yugama crater lake, Kusatsu-Shirane volcano, Japan. Geochem J 28:199-216

Taran I, Peiffer L (2009) Hydrology, hydrochemistry, and geothermal potential of El Chichón volcano hydrothermal system, Mexico. Geothermics 38:370-378

Taran Y, Rouwet D (2008) Estimating thermal inflow to El Chichón crater lake using the energy-budget, chemical and isotope balance approaches. J Volcanol Geotherm Res 175:472-481

Taran Y, Fischer TP, Pokrovsky B, Sano Y, Armienta MA, Macías JL (1998) Geochemistry of the volcano-hydrothermal system of El Chichón volcano, Chiapas, Mexico. Bull Volcanol 59:436449

Taran Y, Rouwet D, Inguaggiato S, Aiuppa A (2008) Major and trace element geochemistry of neutral and acidic thermal springs at El Chichón volcano, Mexico. Implications for monitoring of the volcanic activity. J Volcanol Geotherm Res 178:224-236 
Telling J, Dufek J (2012) An experimental evaluation of ash aggregation in explosive volcanic eruptions. J Volcanol Geotherm Res 209:1-8

Telling J, Dufek J, Shaikh A (2013) Ash aggregation in explosive volcanic eruptions. Geophys Res Lett 40:2355-2360

Templos LA, Munguia Bracamontes F, Barrera VM (1981) Observaciones geoquímicas en la zona geotérmica del Chichonal, Chiapas, Mexico. Unpublished report. Comisión Federal de Electricidad, Mexico. Inf 33-81:32 pp

Textor C, Graf HF, Herzog M, Oberhuber JM, Rose WI, Ernst GGJ (2006a) Volcanic particle aggregation in explosive eruption columns. Part I: parameterization of the microphysics of hydrometeors and ash. J Volcanol Geotherm Res 150:359-377

Textor C, Graf HF, Herzog M, Oberhuber JM, Rose WI, Ernst GGJ (2006b) Volcanic particle aggregation in explosive eruption columns. Part II: numerical experiments. J Volcanol Geotherm Res 150:378-394

Tomita K, Kanai T, Kobayashi T, Oba N (1985) Accretionary lapilli formed by the eruption of Sakurajima volcano. J Jpn Assoc Miner Petrol Econ Geol 80:49-54
Van Eaton AR, Wilson CJN (2013) The nature, origin, and distribution of ash aggregates in large-scale wet eruption deposit: Oruanui, New Zealand. J Volcanol Geotherm Res 250:129-154

Van Eaton A, Muirhead JD, Wilson CJN, Cimarelli C (2012a) Growth of volcanic ash aggregates in the presence of liquid water and ice: an experimental approach. Bull Volcanol 74:1963-1984. doi:10.1007/ s00445-012-0634-9

Van Eaton A R, Herzog M, Wilson, CJN, Mc Gregor J (2012b) Ascent dynamics of large phreatomagmatic eruption clouds: the role of microphysics. J Geophys Res 117 (B03203)

Varekamp JC, Luhr JF, Prestegaard KL (1984) The 1982 eruption of El Chichón volcano (Chiapas, Mexico): character of the eruptions, ash fall deposits and gas phase. J Volcanol Geotherm Res 23:36-68

Veitch G, Woods AW (2001) Particle aggregation in volcanic eruption columns. J Geophys Res 106(B11):26,425-426,441

Wilson CJN (2001) The 26.5 ka Oruanui eruption, New Zealand: an introduction and overview. J Volcanol Geotherm Res 112:133-174 